\title{
Modelling the cost differential between healthy and current diets: the New Zealand case study
}

\author{
Stefanie Vandevijvere ${ }^{1 *}$, Nick Young ${ }^{2}$, Sally Mackay ${ }^{1}$, Boyd Swinburn ${ }^{1}$ and Mark Gahegan²
}

\begin{abstract}
Background: Evidence on whether healthy diets are more expensive than current diets is mixed due to lack of robust methodology. The aim of this study was to develop a novel methodology to model the cost differential between healthy and current diets and apply it in New Zealand.

Methods: Prices of common foods were collected from 15 supermarkets, 15 fruit/vegetable stores and from the Food Price Index. The distribution of the cost of two-weekly healthy and current household diets was modelled using a list of commonly consumed foods, a set of min and max quantity/serves constraints for each, and food group and nutrient intakes based on dietary guidelines (healthy diets) or nutrition survey data (current diets). The cost differential between healthy and current diets was modelled for several diet, prices and policy scenarios. Acceptability of resulting meal plans was validated.
\end{abstract}

Results: The average cost of healthy household diets was $\$ 27$ more expensive than the average cost of current diets, but $25.8 \%$ of healthy diets were cheaper than the average cost of current diets. This cost differential could be reduced if fruits and vegetables became exempt from Goods and Services Tax. Healthy diets were cheaper with an allowance for discretionary foods and more expensive when including takeaway meals. For Mãori and Pacific households, healthy diets were on average $\$ 40$ and $\$ 60$ cheaper than current diets due to large energy intakes. Discretionary foods and takeaway meals contributed $30-40 \%$ to the average cost of current diets.

Conclusion: Healthy New Zealand diets were on average more expensive than current diets, but one-quarter of healthy diets were cheaper than the average cost of current diets. The impact of diet composition, types of prices and policies on the cost differential was substantial. The methodology can be used in other countries to monitor the cost differential between healthy and current household diets.

Keywords: Cost, Healthy diets, Food prices, Modelling, INFORMAS, Ethnic diets

\section{Background}

Unhealthy diets contribute to increasing obesity and dietrelated non-communicable diseases (NCDs) [1]. The cost of food is a major determinant of food choices [2, 3]. Some countries have implemented health-related taxes or subsidies in an effort to improve population diets [4]. Taxes on sugar-sweetened beverages (SSB) are increasingly common internationally [5], and have shown to significantly reduce SSB purchases, especially in lower socio-economic

\footnotetext{
* Correspondence: s.vandevijvere@auckland.ac.nz

'School of Population Health, Department of Epidemiology and Biostatistics, The University of Auckland, Private Bag 92019, Auckland 1142, New Zealand Full list of author information is available at the end of the article
}

population groups [6, 7]. In addition, some countries do not tax healthy foods, for example, in Australia, there is no Goods and Services Tax (GST) on basic healthy foods [8].

Evidence on whether or not healthier diets or dietary patterns are more expensive than less healthy diets is mixed [9]. Currently there is no robust methodology available to adequately answer that question. Most previous studies did not sufficiently take into account the variation in possible diets or food prices, or measured only the cost of the healthy diet [9]. Healthy diets are usually based on food-based dietary guidelines, and are developed by substituting items in a typical diet with healthier items, by developing a diet to meet food-based dietary guidelines or 
based on a typical diet of those who meet dietary guidelines. Some studies used linear programming to develop healthy diets that meet nutrition recommendations for a minimum cost [10]. There are a few previous studies that did measure the cost differential between healthy and current diets, but they compared the cost of only one healthy diet with one current, less healthy population diet [11-15]. The variation of the cost of diets is important when considering the relative cost differential between healthy and current diets, but is currently unknown. Many diet scenarios can be constructed using a list of commonly consumed foods to meet nutrient and food-based dietary guidelines (for 'healthy' diets) or specified population nutrient and food intakes (for 'current' diets). The International Network for Food and Obesity/NCDs Research, Monitoring and Action Support (INFORMAS) [16] developed a useful framework to monitor the cost differential between healthy and current population diets globally [17]. Such monitoring aims to provide robust data and benchmarks to inform economic and fiscal policy responses.

Within the INFORMAS framework for monitoring the cost of population diets, this study developed a new tool and methodology, DIETCOST, and modelled, for the first time, the cost differential between current household diets and healthy household diets in New Zealand, taking into account the variations in two-weekly household meal plans and food prices. The cost differential between healthy and current household diets was compared between different ethnic population groups and for a series of diet and prices scenarios. In addition, the potential impact of two policy scenarios (fresh and frozen vegetables exempt from GST and a tax on SSBs) on the cost differential was modelled, and the Food Price Index (FPI) data was used to model the cost of current New Zealand household diets over a ten year period.

\section{Methods}

The study was approved by the Human Participants Ethics Committee of the University of Auckland (ref 12330). A novel DIETCOST programme [18] was developed for researchers, using Python, to model the cost of healthy and current household diets using a list of commonly consumed foods, a set of min and max quantity/serves constraints for each, and specified food group and nutrient intakes based on dietary guidelines (healthy diets) and nutrition survey data (current diets for different population groups).

The programme was applied in New Zealand as a case study for the total population and specific ethnic population groups.

The reference household comprised a 45-year old man, a 45-year old woman, a 14-year old boy and a 7-year old girl.

\section{Inputs}

The following inputs were prepared as Excel files:

\section{- List of commonly consumed foods}

The lists of common foods for the total population and the different ethnic population groups (Mãori and Pacific populations) were derived from the New Zealand adult nutrition survey and the New Zealand children's food and drink survey [19-22]. Foods within the different groups were included if consumed by more than $5 \%$ of the population. The resulting common foods list for Māori and Pacific populations was additionally checked by experts from Toi Tangata (for Māori) and Pacific Heartbeat (for Pacific) and a few items were deleted or added. Some foods were only included for children or only for adults dependent on consumption frequencies from surveys and advice from the expert panels. The final common foods list contained about 120-133 food and takeaway items dependent on the population group.

\section{- Nutrition targets and constraints}

The energy requirement for healthy adult diets was calculated using the Body Weight Calculator [23] based on a weight derived from a Body Mass Index (BMI) of $23 \mathrm{~kg} / \mathrm{m}^{2}$, a mean population height [24], and moderate physical activity. The energy requirement for healthy children's diets was based on the recommended energy requirements per $\mathrm{KJ} / \mathrm{kg}$ per day from $\mathrm{FAO} / \mathrm{WHO} / \mathrm{UNU}$ [25] for moderate physical activity. The target weight was calculated using the 50th percentile BMI from the CDC growth charts [26] using mean height [24]. The energy requirement for current adult diets was based on the current BMI and moderate physical activity as over half of New Zealand adults meet the physical activity guidelines [24]. The energy requirement for current children's diets was based on actual weight [24] and moderate physical activity as most children meet the New Zealand physical activity guidelines [27]. The additional energy required for the actual weight was calculated using a validated equation [28] for the excess energy intake per unit excess weight in childhood.

The daily food group and nutrient targets included serves of fruit, starchy and non-starchy vegetables, dairy, protein sources and grains, percentage of energy from fats, saturated fats, carbohydrates, protein, and total sugars, amount $(\mathrm{g} / \mathrm{mg})$ of fibre, red meat and sodium, and for certain scenarios the percentage of energy from alcohol and/or discretionary foods. For the healthy diet, these targets were derived from the serve sizes recommended in the New Zealand Eating and Activity Guidelines [29, 30] and the acceptable macronutrient distribution ranges, upper limit (sodium) and suggested dietary target (fibre) from the Nutrient Reference Values for Australia and New Zealand [31]. For the current diets, these targets were derived from average intakes reported in the nutrition surveys [19-22] and for sodium using a later survey which performed 24-h 
urine collection [32]. For current diets, about $30 \%$ of variation was allowed around the average population intakes for each of the targets, except for energy intake, where only $1.5 \%$ of variation was allowed.

\section{- Healthy and current diet baskets}

The common foods list was used to generate the list of foods in the current and healthy diet baskets. The current diet basket for the total population contained 100 foods (including takeaways, excluding alcohol), while the healthy diet basket contained 73 foods (excluding takeaways and alcohol). Takeaway items and discretionary foods were included in the standard current diets but not in the standard healthy diets. Alcohol was only included in the diets for specific scenarios.

Compared to the current diet, the healthy diet basket contained a higher variety of fruits and vegetables, healthier versions of common foods (e.g. canned tomatoes without added salt, some wholegrain or wholemeal products, low fat yoghurt) and a limit on the consumption of red meat (maximum $100 \mathrm{~g}$ per day). For each common food, minimum and maximum serve sizes were set based on nutrition survey data, to avoid unrealistic amounts of any one food in the generated meal plans.

\section{Food composition data}

Nutrient composition data and edible cooking factors for the common foods were used from the New Zealand Food Composition Database [33] and the New Zealand Nutritrack database of packaged food products [34].

\section{Food prices data}

Two sources of prices data were used:

- Prices were collected in spring (November 2016) in 12 Auckland supermarkets and their nearest fruit and vegetables store, in areas with different levels of deprivation. For each common food the cheapest price was collected, and the original price was also collected if the cheapest price was discounted. Prices of fruit and vegetables were collected in supermarkets as well as fruit and vegetable stores. In addition, for 6 out of 12 supermarkets, if the cheapest food was a generic item, the cheapest branded item was also collected. Based on consultations with Toi Tangata, a few common fruits and vegetables (e.g. feijoas, kamo kamo, puha, watercress) were included with zero cost for Māori, as these would always be gifted or gathered, not purchased. Based on advice from Pacific Heartbeat, for Pacific households prices were collected in 3 different additional supermarkets in South Auckland and fruit and vegetables were only priced from fresh produce markets.

- The Food Price Index (FPI) data for New Zealand [35] was used for the period 2007-2016 to examine trends in the cost of current New Zealand population diets over time. As some healthier options for certain food groups were not included in this dataset (e.g. low salt or low fat products, wholegrain foods, butter but no margarine), trends in cost of healthy diets were not assessed using the FPI. Items in the FPI are selected based on their expenditure in the Household Economic Survey. Prices are collected monthly from 56 supermarkets across 12 regional centres and from fresh fruit and vegetable stores, fish shops, butchers, convenience stores, restaurants and takeaway food outlets [35].

\section{Interface}

The programme user interface [18] allows the user to specify the daily targets for the food groups and nutrients for all household members for current and healthy diets separately. In addition, the interface allows the user to specify whether or not to include takeaway meals, alcohol and discretionary foods as part of the diets.

The minimum serve size difference between any two generated individual meal plans was set at half a serve for any common food in this study.

The programme algorithm uses the Mersenne Twister as a random number generator to specify the starting meal plan and the starting value in grams for each of the common foods. If a meal plan meets all targets/constraints and is not already in the list of matching meal plans, it is added to the results. If it doesn't (i.e. it fails some constraint), the algorithm will then try to fix that constraint (by raising/lowering the amount of some item that affects that constraint randomly between the min and max amount for that food item). If the modification results in a matching meal plan the meal plan is added to the results, and the same procedure starts again until the specified number of iterations has been run (Fig. 1). If the modification does not result in a matching meal plan, the algorithm will continue to try to resolve one of the failing constraints in a subsequent iteration. All success meal plans are independent from each other.

For each individual household member, the current and healthy diet scenarios were run multiple times with $1 \mathrm{mil}$ lion, 2million and 20million iterations respectively to find the right number of iterations needed to accurately estimate the average cost of healthy and current household diets.

\section{Validation of menu plans}

A random selection of meal plans $(N=8,4$ for the healthy and 4 for the current diets) for the different household members generated by the programme was validated by a research assistant who made fortnightly household meal 


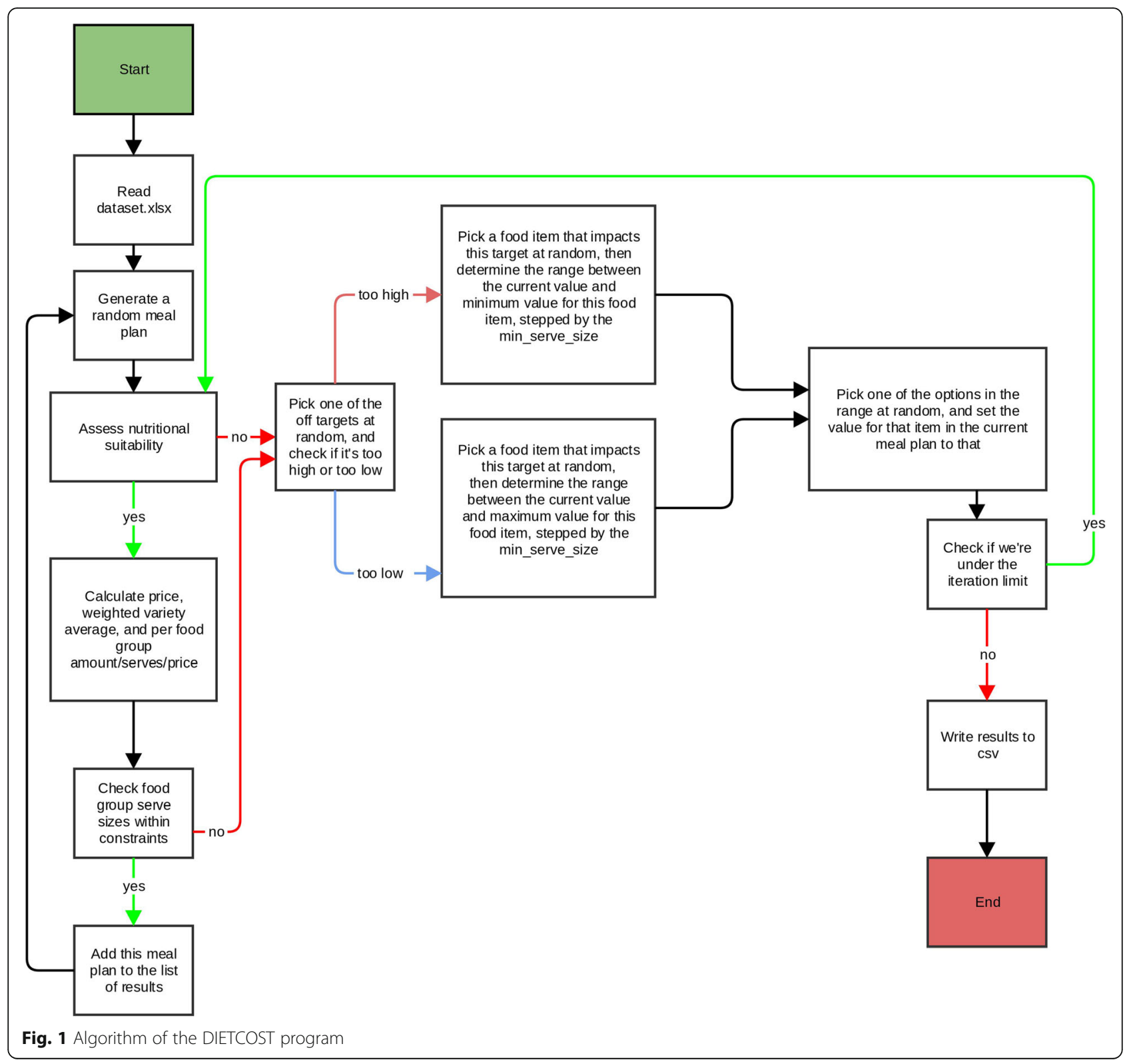

plans with the same amount of common foods manually to make sure that the meal plans were acceptable. A few food items were linked within the programme to ensure the resulting meal plans are acceptable, e.g. the programme code specified that the total number of serves of milk needs to be higher than or equal to the total number of serves of breakfast cereals and the total number of serves of spreads equal or lower than the total number of serves of bread and crackers.

\section{Statistical analysis}

All possible combinations of two-weekly meal plans for the four individual household members were assembled into two-weekly household diets for healthy and current diets separately. The range and distribution of the cost of the fortnightly household meal plans and the contributions of each food group and discretionary foods, alcohol and takeaways to the cost of the diets was calculated.

The impact of different prices, diets and policy scenarios on the cost differential between healthy and current household diets was also calculated.

\section{Results}

About 1 million iterations allowed an accurate estimation of the average cost of healthy household diets, while about 2 million iterations were needed for an accurate estimation of the average cost of current household diets in New Zealand. 


\section{Standard healthy and current diets for the total New Zealand population}

The energy density of the average current household diet was about 50\% higher than for the average healthy household diet. Current diets were all found less healthy than the healthy diets as, for example for the adult men, 0 meal plans met all healthy diet guidelines due to 0 meal plans meeting maximum sodium intake, minimum fibre intake and minimum number of serves of fruit (Additional file 1: Table S1).

The average fortnightly cost of healthy New Zealand household diets was about \$27 more expensive than the average cost of current New Zealand household diets (Table 1). However, about $25.8 \%$ of healthy diets were cheaper than the cost of the average current household diets, and the cheapest healthy household diet was cheaper than the cheapest current diet (Fig. 2). The variation around the average cost was greater for healthy than for current diets and the range of costs of current diets fell within the range of costs of healthy diets (Table 1; Fig. 2).

Discretionary foods (including beverages) and takeaways contributed about $35.5 \%$ to the cost of the average current diet, while fruits and vegetables contributed about $19 \%$ to the average cost. Healthy diets did not contain takeaways and discretionary foods but fruits and vegetables contributed about $40 \%$ to the average cost of healthy diets. Protein sources were the major contributor to the cost of healthy and current diets and contributed on average more or less one third to the cost of both healthy and current diets, while dairy contributed about $5 \%$ to the cost of current versus $13 \%$ to the cost of healthy diets (Fig. 3).

\section{Diets for different ethnic population groups}

When healthy and current household diets were modelled for specific ethnic New Zealand populations, fortnightly healthy household diets were less expensive on average than fortnightly current household diets; with an average differential of about $\$ 60$ dollars for Pacific and $\$ 40$ for Māori (Table 1). About $87.1 \%$ of healthy diets were cheaper than the average cost of current Mãori diets, while $96.7 \%$ of healthy diets were cheaper than the average cost of current Pacific diets (Fig. 2). The current average energy intakes for both Pacific and Māori household members, based on the energy required to maintain the current BMI, were between 3 and 9\% and 5-10\% higher than for the total New Zealand population respectively (data not shown). The energy density of the current diets was highest on average for Māori households (Table 1).

Discretionary foods and takeaways contributed 35.5\% and 39.3\% to the average cost of Pacific and Māori current diets, while fruits and vegetables contributed $16 \%$ and $12 \%$ to the average cost respectively. Healthy diets did not contain takeaways and discretionary foods but fruits and vegetables contributed about $46 \%$ and $43 \%$ to the average cost of healthy diets for Māori and Pacific households respectively (Fig. 3).

\section{Diet, prices and policy scenarios}

The average cost of the healthy diet was substantially more expensive for all population groups with inclusion of takeaways (healthier options such as sushi, sandwich) and substantially cheaper with an allowance for discretionary foods (Table 2). The latter was not the case for Māori populations since some fruit and vegetables are included in those diets for free (as Māori would never buy those foods). With an allowance for discretionary foods, the average cost of healthy diets was the same as the average cost of current diets for the total New Zealand population (Table 2). When allowing for the same energy intake in the healthy as in the current diet, the average cost of the healthy diet was $\$ 70$ more expensive over a

Table 1 Average (SD) cost in New Zealand dollars and energy density of two-weekly standard household healthy and current, less healthy diets ${ }^{a}$ for the total New Zealand population and for Māori and Pacific population groups separately

\begin{tabular}{|c|c|c|c|c|c|c|}
\hline & \multicolumn{2}{|l|}{ Total NZ population } & \multicolumn{2}{|l|}{ Pacific population } & \multicolumn{2}{|l|}{ Māori population } \\
\hline & Healthy diets & Current diets & Healthy diets & Current diets & Healthy diets & Current diets \\
\hline $\mathrm{N}$ iterations & $1,000,000$ & $2,000,000$ & $1,000,000$ & $2,000,000$ & $1,000,000$ & $2,000,000$ \\
\hline $\begin{array}{l}\text { N common foods } \\
\text { included }\end{array}$ & 73 & 100 & 71 & 105 & 75 & 109 \\
\hline $\mathrm{N}$ individual meal plans & $\begin{array}{l}365+347+319+ \\
137\end{array}$ & $\begin{array}{l}360+185+96+ \\
153\end{array}$ & $\begin{array}{l}120+226+299+ \\
281\end{array}$ & $\begin{array}{l}252+452+330+ \\
329\end{array}$ & $93+137+17+44$ & $\begin{array}{l}332+127+12+ \\
367\end{array}$ \\
\hline $\mathrm{N}$ household meal plans & $5,960,900,400$ & $978,220,800$ & $2,278,595,280$ & $12,366,557,280$ & $9,530,268$ & $185,690,256$ \\
\hline Average cost (SD) & $\$ 723.4(75.7)$ & $\$ 696.3(48.5)$ & $\$ 593.7(65.0)$ & $\$ 655.1(62.6)$ & $\$ 655.3(65.0)$ & $\$ 693.6(43.1)$ \\
\hline Range of the cost & $\$ 502.0-\$ 937.1$ & $\$ 571.1-\$ 850.0$ & $\$ 423.4-\$ 778.3$ & $\$ 448.6-\$ 799.6$ & $\$ 522.0-\$ 790.7$ & $\$ 580.3-\$ 796.3$ \\
\hline Energy $(\mathrm{MJ})^{\mathrm{b}}$ & 139.6 (137.6-141.7) & $152.2(150.3-154.8)$ & $139.6(137.6-141.7)$ & $165.7(163.8-168.7)$ & 139.7 (137.6-141.4) & $161.4(159.4-164.1)$ \\
\hline Energy density $(\mathrm{kJ} / \mathrm{g})^{\mathrm{b}}$ & 1.02 & 1.49 & 1.03 & 1.56 & 0.94 & 1.65 \\
\hline
\end{tabular}

SD standard deviation

${ }^{a}$ No alcohol, takeaways or discretionary foods included in the standard healthy diet; takeaways and discretionary foods included in the current diet ${ }^{\mathrm{b}}$ Average (range) 


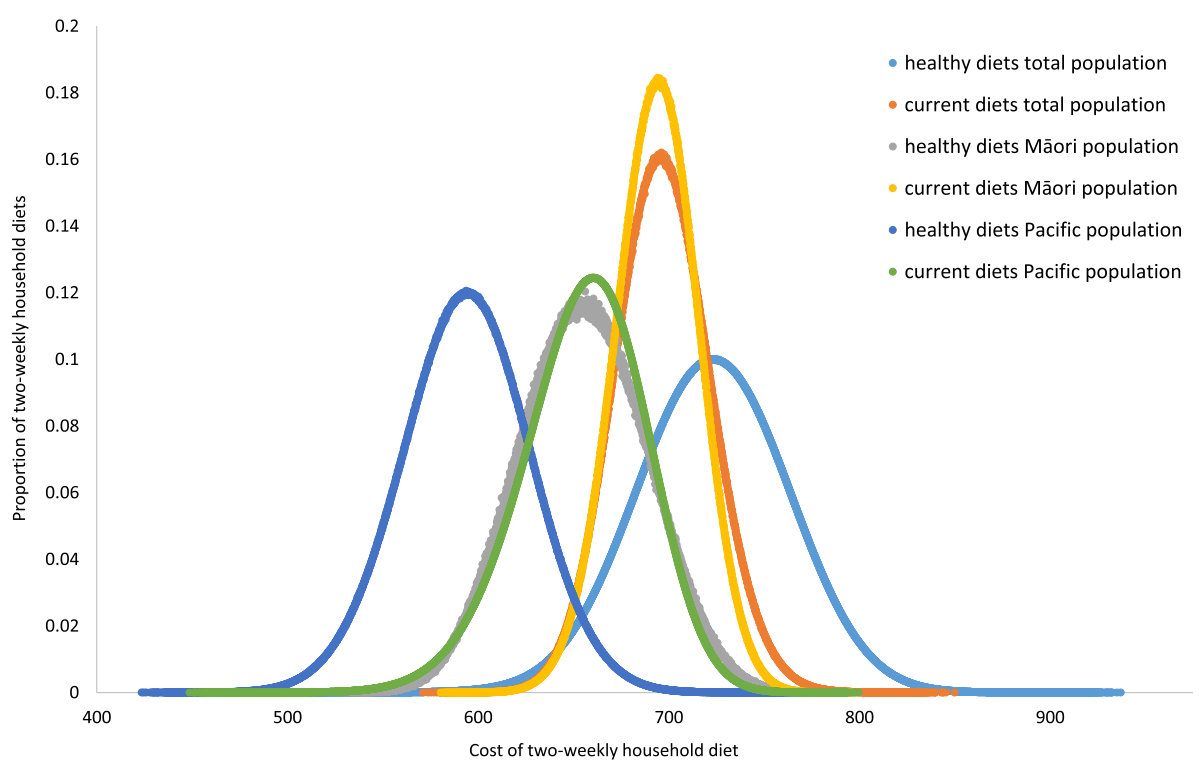

Fig. 2 Distribution of the two-weekly cost of healthy (1,000,000 iterations) and current (2,000,000 iterations) household diets for the total New Zealand population and for Māori and Pacific population groups separately

fortnight than the standard healthy diet and when allowing takeaways and alcohol at the same time, the average cost was $\$ 105$ dollars more expensive over a fortnight (Table 2).

When buying common foods at a discount whenever possible, the cost of the average healthy diet was about $\$ 14$ per fortnight less expensive on average than when foods were not bought on discount.
The same applies for buying generic products instead of brands, where the average healthy diet, when including generics, where available was $\$ 30$ cheaper. Results for these scenarios were similar for current diets (Table 3).

In the case where GST would be removed from fresh and frozen fruits and vegetables in New Zealand, such as in Australia, this would substantially reduce the cost

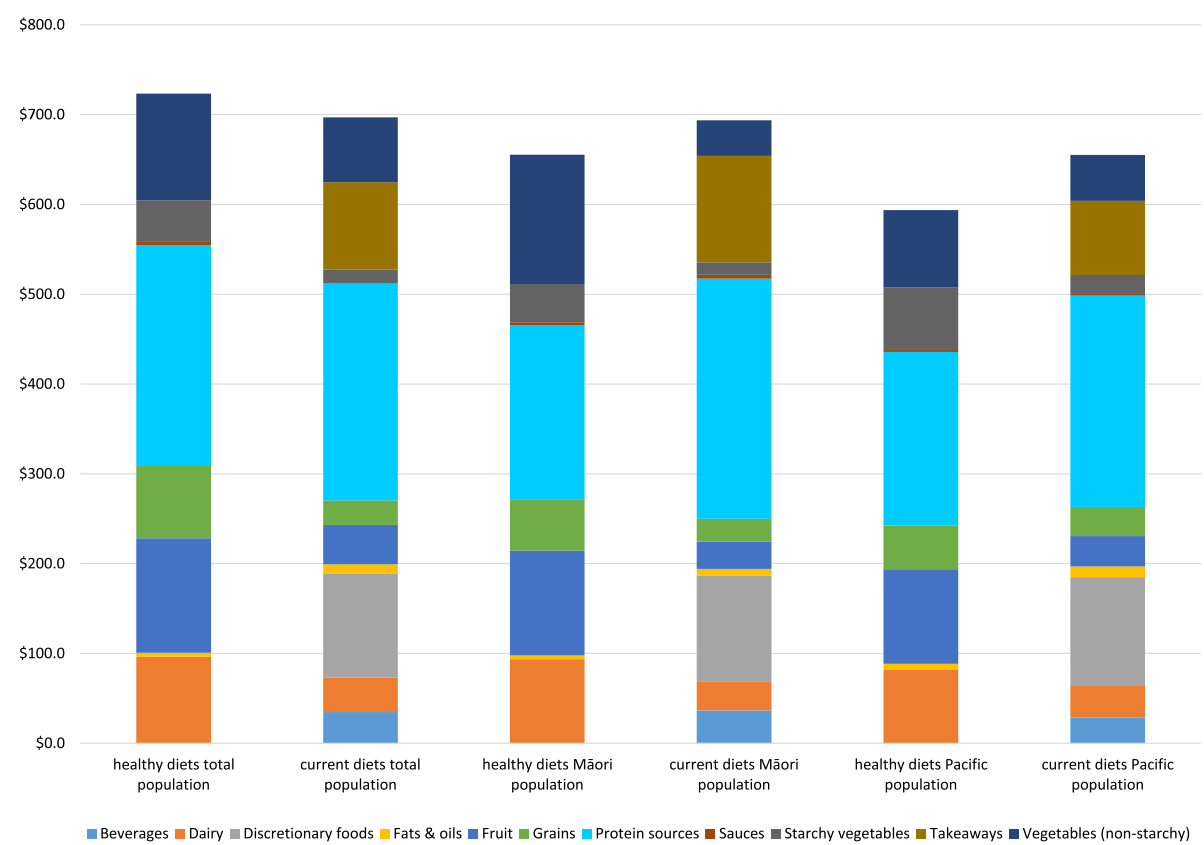

Fig. 3 Contribution of food groups to the average cost of current and healthy diets for the total population and Māori and Pacific populations in New Zealand 
Table 2 Average (SD) cost in New Zealand dollars of two-weekly healthy and current, less healthy household diets ${ }^{\mathrm{a}}$ for the total New Zealand population and for Māori and Pacific populations separately with and without allowance for takeaways, alcohol and discretionary foods

\begin{tabular}{|c|c|c|c|c|c|c|}
\hline & \multicolumn{2}{|c|}{ Total NZ population } & \multicolumn{2}{|c|}{ Pacific population } & \multicolumn{2}{|c|}{ Māori population } \\
\hline & $\begin{array}{l}\text { Healthy } \\
\text { diets }\end{array}$ & $\begin{array}{l}\text { Current } \\
\text { diets }\end{array}$ & $\begin{array}{l}\text { Healthy } \\
\text { diets }\end{array}$ & $\begin{array}{l}\text { Current } \\
\text { diets }\end{array}$ & $\begin{array}{l}\text { Healthy } \\
\text { diets }\end{array}$ & $\begin{array}{l}\text { Current } \\
\text { diets }\end{array}$ \\
\hline \multicolumn{7}{|c|}{ Changes to the diets - scenarios } \\
\hline Standard diets (as per Table 1) ${ }^{a}$ & $\begin{array}{l}\$ 723.4 \\
(75.7)\end{array}$ & $\begin{array}{l}\$ 696.3 \\
(48.5)\end{array}$ & $\begin{array}{l}\$ 593.7 \\
(65.0)\end{array}$ & $\begin{array}{l}\$ 655.1 \\
(62.6)\end{array}$ & $\begin{array}{l}\$ 655.3 \\
(65.0)\end{array}$ & $\begin{array}{l}\$ 694.4 \\
(49.1)\end{array}$ \\
\hline Including takeaways & $\begin{array}{l}\$ 760.4 \\
(81.7)\end{array}$ & $\begin{array}{l}\$ 696.3 \\
(48.5)\end{array}$ & $\begin{array}{l}\$ 615.8 \\
(74.2)\end{array}$ & $\begin{array}{l}\$ 655.1 \\
(62.6)\end{array}$ & $\begin{array}{l}\$ 689.3 \\
(70.7)\end{array}$ & $\begin{array}{l}\$ 694.4 \\
(49.1)\end{array}$ \\
\hline Including alcohol and takeaways & $\begin{array}{l}\$ 767.2 \\
(85.6)\end{array}$ & $\begin{array}{l}\$ 720.5 \\
(49.3)\end{array}$ & $\begin{array}{l}\$ 626.5 \\
(75.6)\end{array}$ & $\begin{array}{l}\$ 677.2 \\
(63.2)\end{array}$ & $\begin{array}{l}\$ 699.1 \\
(78.4)\end{array}$ & $\begin{array}{l}\$ 712.4 \\
(44.4)\end{array}$ \\
\hline Including discretionary foods & $\begin{array}{l}\$ 697.8 \\
(65.0)\end{array}$ & $\begin{array}{l}\$ 696.3 \\
(48.5)\end{array}$ & $\begin{array}{l}\$ 576.7 \\
(58.4)\end{array}$ & $\begin{array}{l}\$ 655.1 \\
(62.6)\end{array}$ & $\begin{array}{l}\$ 659.7 \\
(65.6)\end{array}$ & $\begin{array}{l}\$ 694.4 \\
(49.1)\end{array}$ \\
\hline Including discretionary foods, alcohol and takeaways & $\begin{array}{l}\$ 733.3 \\
(70.3)\end{array}$ & $\begin{array}{l}\$ 720.5 \\
(49.3)\end{array}$ & $\begin{array}{l}\$ 605.9 \\
(59.1)\end{array}$ & $\begin{array}{l}\$ 677.2 \\
(63.2)\end{array}$ & $\begin{array}{l}\$ 694.8 \\
(83.7)\end{array}$ & $\begin{array}{l}\$ 712.4 \\
(44.4)\end{array}$ \\
\hline \multicolumn{7}{|c|}{ Changes to the energy intake of the healthy diet - scenarios } \\
\hline $\begin{array}{l}\text { Same energy in current and healthy diet - without alcohol and } \\
\text { takeaways }\end{array}$ & $\begin{array}{l}\$ 793.9 \\
(80.0)\end{array}$ & $\begin{array}{l}\$ 696.3 \\
(47.9)\end{array}$ & $\begin{array}{l}\$ 707.3 \\
(74.4)\end{array}$ & $\begin{array}{l}\$ 655.1 \\
(62.6)\end{array}$ & $\begin{array}{l}\$ 777.8 \\
(61.8)\end{array}$ & $\begin{array}{l}\$ 694.4 \\
(49.1)\end{array}$ \\
\hline $\begin{array}{l}\text { Same energy in current and healthy diet - with alcohol and } \\
\text { takeaways }\end{array}$ & $\begin{array}{l}\$ 828.7 \\
(85.6)\end{array}$ & $\begin{array}{l}\$ 720.5 \\
(49.3)\end{array}$ & $\begin{array}{l}\$ 758.4 \\
(73.9)\end{array}$ & $\begin{array}{l}\$ 677.2 \\
(63.2)\end{array}$ & $\begin{array}{l}\$ 798.7 \\
(72.5)\end{array}$ & $\begin{array}{l}\$ 712.4 \\
(44.4)\end{array}$ \\
\hline
\end{tabular}

SD standard deviation

${ }^{a}$ No alcohol, takeaways or discretionary foods included in the healthy diet; takeaways and discretionary foods included in the current diet

differential between the healthy and current diets, to the extent that the average cost differential almost disappears. On the other hand, implementing a sugary drinks tax had only minimal impact on the cost differential between healthy and current diets in New Zealand, although it does reduce the average cost differential a bit further (Table 3).

\section{Trends in the cost of the New Zealand population diet over time}

Using the Food Price Index data over 10 years, the cost of current diets was a bit more expensive, since not all prices collected as part of the FPI are necessarily the cheapest prices. Based on this data, the cost of current household diets substantially increased over time. The contribution to the cost of different food groups was very similar across seasons though vegetables tend to contribute more to the cost in winter (Fig. 4, Additional file 1: Fig. S1).

\section{Discussion}

This study developed a new tool and methodology, DIETCOST, to model the cost differential between healthy and current population diets, and applied it as a case study in New Zealand.

Table 3 Comparison of the average (SD) cost in New Zealand dollars of two-weekly standard healthy and current, less healthy diets ${ }^{\mathrm{a}}$ for the total New Zealand population for different pricing and policy scenarios

\begin{tabular}{|c|c|c|}
\hline & Healthy diet & Current diet \\
\hline \multicolumn{3}{|c|}{ Prices scenarios } \\
\hline Non-discount prices only & $\$ 730.0(75.8)$ & $\$ 700.2(52.0)$ \\
\hline Discount prices included & $\$ 716.4(73.0)$ & $\$ 688.9(48.4)$ \\
\hline Prices for branded products only & $\$ 739.4(73.6)$ & $\$ 712.4(48.9)$ \\
\hline Prices for generic products included & $\$ 706.0(75.5)$ & $\$ 681.9(48.9)$ \\
\hline Fruit and vegetables from supermarkets & $\$ 738.5(73.8)$ & $\$ 692.7(48.9)$ \\
\hline Fruit and vegetables from fresh produce stores & $\$ 706.3(74.2)$ & $\$ 691.6(47.7)$ \\
\hline \multicolumn{3}{|c|}{ Policy scenarios } \\
\hline Leaving GST off fresh fruit and vegetables ${ }^{a}$ & $\$ 681.5(72.2)$ & $\$ 671.0(43.3)$ \\
\hline Leaving GST off fresh fruit and vegetables and a $20 \%$ soda tax ${ }^{a}$ & $\$ 681.5(72.2)$ & $\$ 676.1(43.5)$ \\
\hline
\end{tabular}

SD standard deviation, GST Goods and Services Tax

${ }^{a} \mathrm{No}$ alcohol, takeaways or discretionary foods in the healthy diet; takeaways and discretionary foods included in the current diet 
For the New Zealand population, healthy diets were on average \$27 more expensive than current diets over a fortnight in New Zealand, but one-quarter of healthy diets were cheaper than the average current diet. For Māori and Pacific population groups, however, in view of their high current energy intakes, current household diets were on average \$40-60 more expensive than healthy diets. Healthy diets for Māori and Pacific households are generally cheaper than for the total population because of several factors, e.g. prices in South Auckland supermarkets and fresh produce markets were cheaper (where Pacific populations live and shop), some fruits and vegetables, like feijoas, puha, kamo kamo, were included in the Māori diets for free since they would be gifted or gather these foods, and healthy Māori diets did not contain lower salt/fat/sugar versions of products.

Strengths of the study include the development and validation of a new programme, DIETCOST, to generate shopping lists for two-weekly meal plans that meet the targets and constraints for both the current and the healthy diets. In addition, common foods and nutrient and food group targets for different ethnic groups allowed conducting the modelling for specific ethnic populations. Unlike studies to date that have compared the cost of one healthy and one current diet, DIETCOST allows the cost of many fortnightly household diets to be generated enabling comparing the distribution of costs of current and healthy diets. DIETCOST provides a tool to calculate the cost of many meal plans for a range of scenarios of changing the diet contents, altering the type of price, location or reference household, without the need to do this manually. The programme can be readily used and applied with other population groups in other countries and contexts after adapting the input files. Limitations of the study include the fact that New Zealand lacks up-to-date nutrition survey data as the latest survey was conducted in 2008. A new nutrition survey needs to be conducted urgently and was a key recommendation in the latest Healthy Food Environment Policy Index report [36]. The Food Price Index is a great resource to look at trends over time, but includes some clear limitations, such as the fact that some key foods are missing and it is not always easy to divide the foods into healthy and less healthy due to insufficient details in the description.

This study adds to the literature through providing a common tool to assess the cost differential between current and healthy diets. Previous studies only priced one healthy and one current diet and used different approaches to identify the diet, define healthiness and calculate the cost [9].

In Australia, it was found that the current diet was more expensive than the healthy diet with more than half of the current household budget for food spent on energy-dense, nutrient-poor foods, which is more than in New Zealand [11]. It needs to be noted however that in Australia fruit and vegetables and basic healthy foods are exempt from GST. In addition, there was no adjustment for underreporting, while this study calculated energy intake based on the current weight of the population rather than using survey data. In Denmark, it was found that the healthy New Nordic diet was about $16 \%$ more expensive than the current diet with the largest relative difference for lowincome households [37].

\section{Conclusions}

The cost of food is an important determinant of food choices. This study developed a novel methodology to

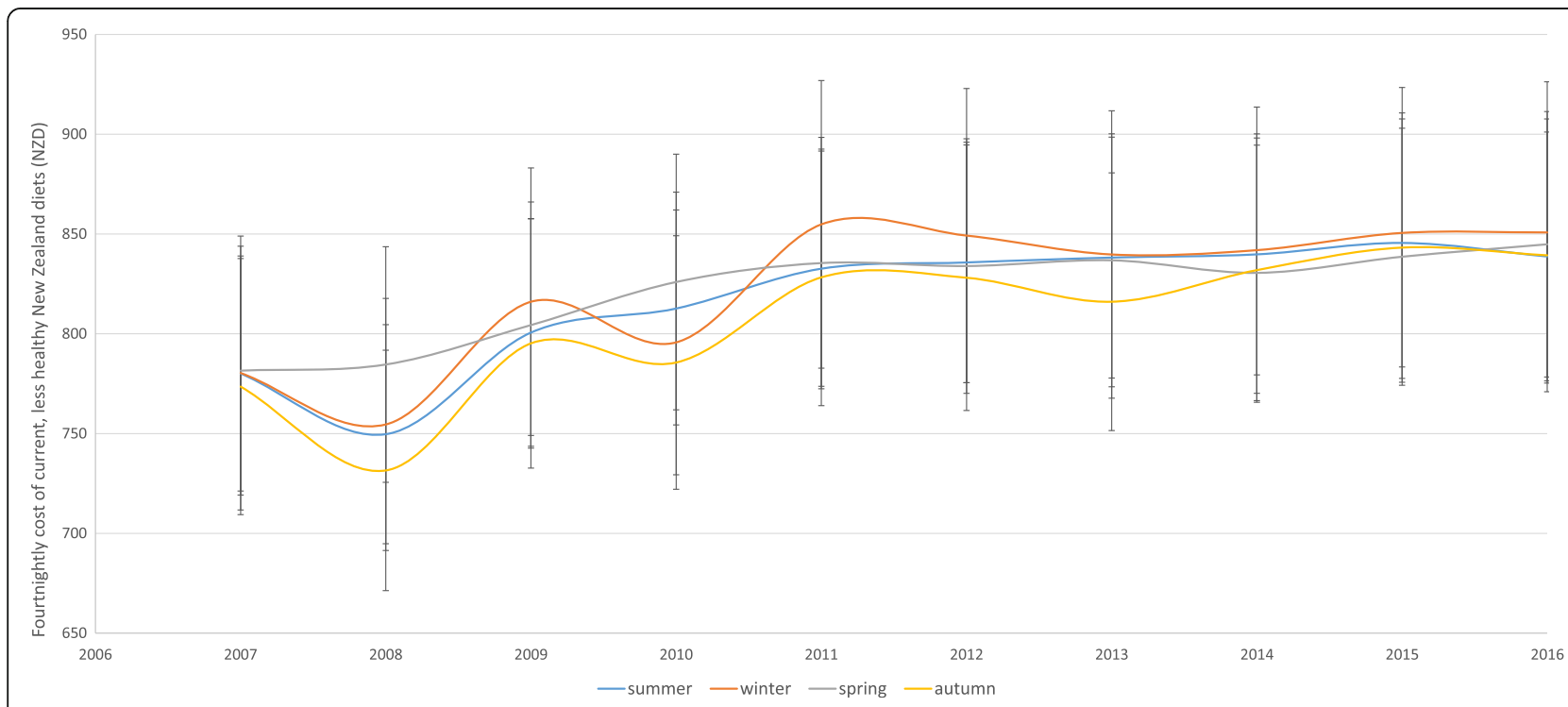

Fig. 4 The average cost of current, less healthy diets over 10 years in New Zealand using the Food Price Index (FPI) prices in different seasons (summer, winter, spring and autumn) 
model the cost differential between healthy and current household diets. Healthy New Zealand diets are on average more expensive than current diets, but not for specific ethnic population groups.

Reducing taxes on fresh and frozen fruit and vegetables in New Zealand in conjunction with a sugary drinks tax could reduce the average cost of healthy diets towards the average of current diets and make it easier for people to consume healthy diets. The same approach as in this study can be applied in countries globally to benchmark the cost differential between current and healthy diets among countries internationally.

\section{Additional file}

Additional file 1: Table S1. Proportion of current diets for adult males $(N=360)$ meeting the guidelines for a healthy diet. Fig. S1. Contributions of different food groups to the average cost of the current, less healthy diet in New Zealand by season (across 10 years). (DOCX 99 kb)

\section{Abbreviations}

BMI: Body Mass Index; CDC: Centres for Disease Control; FPI: Food Price Index; GST: Goods and Services Tax; INFORMAS: International Network for Food and Obesity/NCDs Research, Monitoring and Action Support; NCDs: Non-communicable diseases; SSB: Sugar-sweetened beverages

\section{Acknowledgements}

The authors declare no conflicts of interest exist. SV designed the study and methods, N.Y. and S.M. contributed to development of the methodology, N.Y. developed the DIETCOST programme, S.V. and S.M. produced the results, S.V. wrote the paper and had primary responsibility for final content. All authors read and approved the final manuscript.

\section{Funding}

The study was funded by the Food and Health Programme of the University of Auckland. The funder had no role in the design of the study and collection, analysis, and interpretation of data and in writing the manuscript.

\section{Availability of data and materials}

The datasets used and/or analysed during the current study available from the corresponding author on reasonable request.

\section{Authors' contributions}

SV designed the study, NY developed the DIETCOST programme, SM collected the data, SV and SM analysed and interpreted the data. SV wrote the manuscript and all authors critically commented on draft versions of the manuscript. All authors read and approved the final manuscript.

\section{Ethics approval and consent to participate}

Ethics approval for this research was obtained from the University of Auckland Human Participants Ethics Committee (reference number 012330).

\section{Consent for publication}

Not applicable

\section{Competing interests}

The authors declare that they have no competing interests.

\section{Publisher's Note}

Springer Nature remains neutral with regard to jurisdictional claims in published maps and institutional affiliations.

\section{Author details}

${ }^{1}$ School of Population Health, Department of Epidemiology and Biostatistics, The University of Auckland, Private Bag 92019, Auckland 1142, New Zealand.
${ }^{2}$ Centre for e-Research, Faculty of Science, The University of Auckland, Auckland, New Zealand.

Received: 17 October 2017 Accepted: 19 January 2018

Published online: 09 February 2018

\section{References}

1. Lim SS, Vos T, Flaxman AD, Danaei G, Shibuya K, Adair-Rohani H, et al. A comparative risk assessment of burden of disease and injury attributable to 67 risk factors and risk factor clusters in 21 regions, 1990-2010: a systematic analysis for the Global Burden of Disease Study 2010. Lancet. 2012; 380(9859):2224-60.

2. Glanz K, Basil M, Maibach E, Goldberg J, Snyder D. Why Americans eat what they do: taste, nutrition, cost, convenience, and weight control concerns as influences on food consumption. J Am Diet Assoc. 1998;98(10):1118-26.

3. Lennernäs M, Fjellström C, Becker W, Giachetti I, Schmitt A, Remaut de Winter $\mathrm{A}$, et al. Influences on food choice perceived to be important by nationally-representative samples of adults in the European Union. Eur J Clin Nutr. 1997;51(SUPPL. 2):S8-S15.

4. World Cancer Research Fund. NOURISHING framework: our policy framework to promote healthy diets and reduce obesity 2017 [11/04/2017]. Available from: http://www.wcrf.org/int/policy/nourishing-framework.

5. Backholer K, Blake M, Vandevijvere S. Have we reached a tipping point for sugar-sweetened beverage taxes? Public Health Nutr. 2016;19(17):3057-61.

6. Colchero MA, Popkin BM, Rivera JA, Ng SW. Beverage purchases from stores in Mexico under the excise tax on sugar sweetened beverages: observational study. BMJ. 2016;352:h6704.

7. Falbe J, Thompson HR, Becker CM, Rojas N, McCulloch CE, Madsen KA. Impact of the Berkeley excise tax on sugar-sweetened beverage consumption. Am J Public Health. 2016;106(10):1865-71.

8. Australian Taxation Office. Detailed food list. 20162017 [10/08/2017]. Available from: https://www.ato.gov.au/Business/GST/In-detail/Your-industry/ Food/Detailed-food-list/.

9. Rao M, Afshin A, Singh G, Mozaffarian D. Do healthier foods and diet patterns cost more than less healthy options? A systematic review and meta-analysis. BMJ Open. 2013;3(12):e004277.

10. Maillot M, Darmon N, Drewnowski A. Are the lowest-cost healthful food plans culturally and socially acceptable? Public Health Nutr. 2010;13(8): 1178-85.

11. Lee AJ, Kane S, Ramsey R, Good E, Dick M. Testing the price and affordability of healthy and current (unhealthy) diets and the potential impacts of policy change in Australia. BMC Public Health. 2016;16:315.

12. Donati M, Menozzi D, Zighetti C, Rosi A, Zinetti A, Scazzina F. Towards a sustainable diet combining economic, environmental and nutritional objectives. Appetite. 2016;106:48-57.

13. Friel $\mathrm{S}$, Barosh $\sqcup$, Lawrence $\mathrm{M}$. Towards healthy and sustainable food consumption: an Australian case study. Public Health Nutr. 2014;17(5):1156-66.

14. Germani A, Vitiello V, Giusti AM, Pinto A, Donini LM, del Balzo V. Environmental and economic sustainability of the Mediterranean diet. Int J Food Sci Nutr. 2014;65(8):1008-12.

15. Jetter KM, Cassady DL. The availability and cost of healthier food alternatives. Am J Prev Med. 2006;30(1):38-44.

16. Swinburn B, Sacks G, Vandevijvere S, Kumanyika S, Lobstein T, Neal B, et al. INFORMAS (International Network for Food and Obesity/non-communicable diseases Research, Monitoring and Action Support): overview and key principles. Obes Rev. 2013;14(Suppl 1):1-12.

17. Lee A, Mhurchu CN, Sacks G, Swinburn B, Snowdon W, Vandevijvere S, et al. Monitoring the price and affordability of foods and diets globally. Obes Rev. 2013;14(Suppl 1):82-95.

18. The University of Auckland. DIETCOST 2017 [31/07/2017]. Available from: http://dietcost.cer.auckland.ac.nz/.

19. Ministry of Health. A focus on nutrition: key findings from the $2008 / 09$ NZ adult nutrition survey 2012.

20. Ministry of Health. A focus on Pacific nutrition. Findings from the 2008/09 New Zealand adult nutrition survey. Wellington: Ministry of Health; 2012

21. Ministry of Health. A focus on Māori nutrition: findings from the 2008/09 New Zealand adult nutrition survey. Wellington: Ministry of Health; 2012.

22. New Zealand children's food and drink survey. Wellington: National Research Bureau; 2007 [23/08/2017]. Available from: http://www.hpa.org.nz/ sites/default/files/CFDS-full\%20report-fnl.pdf. Accessed 15 Oct 2017. 
23. National Institute of Diabetes and Digestive and Kidney Diseases. Body weight planner 2017 [31/07/2017]. Available from: https://www.niddk.nih. gov/health-information/weight-management/body-weight-planner.

24. Ministry of Health. Annual update of key results 2013/14: New Zealand health survey. Wellington: Ministry of Health; 2014.

25. Food and Agriculture Organization (FAO). Human energy requirements. Report of a Joint FAO/WHO/UNU Expert Consultation. Rome: FAO; 2004. [31/07/2017]. Available from: http://www.fao.org/docrep/007/y5686e/y5686e00.htm

26. Centers for Disease Control and Prevention (CDC). Growth charts CDC 2017 [31/07/2017]. Available from: https://www.cdc.gov/growthcharts/index.htm.

27. Ministry of Health. A national survey of children and young people's physical activity and dietary behaviours in New Zealand: 2008/09: key findings. Wellington: Ministry of Health; 2010.

28. Hall KD, Butte NF, Swinburn BA, Chow CC. Dynamics of childhood growth and obesity: development and validation of a quantitative mathematical model. Lancet Diabetes Endocrinol. 2013;1(2):97-105.

29. Ministry of Health. Eating and activity guidelines for New Zealand adults. Wellington: Ministry of Health; 2015. [23/08/2017]. Available from: http://www.health.govt.nz/publication/eating-and-activity-guidelines-newzealand-adults

30. Ministry of Health. Eating for healthy children aged 2 to 12/Ngā Kai Tōtika mō te Hunga Köhungahunga. Wellington: Ministry of Health; 2002. [23/08/ 2017]. Available from: https://www.healthed.govt.nz/resource/eatinghealthy-children-aged-2-12ng\%C4\%81-kai-t\%C5\%8Dtika-m\%C5\%8D-tehunga-k\%C5\%8Dhungahunga. Accessed 15 Oct 2017.

31. Australian Government. Nutrient Reference Values for Australia and New Zealand [03/02/2015]. Available from: https:/www.nnv.gov.au/nutrients/sodium.

32. Skeaff SA, McLean R, Mann J. S W. The impact of mandatory fortification of bread with iodine. Ministry for Primary Industries: Wellington; 2013.

33. The New Zealand Institute of Plant \& Food Research Limited. New Zealand food composition database. Auckland: The New Zealand Institute of Plant \& Food Research Limited; 2013. Available from: http://www.foodcomposition.co.nz/.

34. National Institute for Health Innovation. Nutritrack. Reformulation of processed foods to promote health 2011 [20/05/15]. Available from: http://www.foodandhealth.auckland.ac.nz/en/about/news/news-2014/ 2014/05/nutritrack.html.

35. Statistics New Zealand. Consumer price index. Wellington: Statistics New Zealand; 2017. [23/08/2017]. Available from: http://www.stats. govt.nz/browse_for_stats/economic_indicators/cpi_inflation/inforeleases.aspx

36. Vandevijvere S, Mackay S, Swinburn B. Benchmarking food environments: progress by the New Zealand government on implementing recommended food environment policies and prioritized recommendations. Auckland: The University of Auckland; 2017. Available from: https://figshare.com/articles/ Benchmarking_Food_Environments_Progress_by_the_new_Zealand_ Government_on_Implementing_Recommended_Food_Environment Policies_and_Prioritised_recommendations_10.1886/s12966-018-0648-6.

37. Jensen JD, Saxe H, Denver S. Cost-effectiveness of a new nordic diet as a strategy for health promotion. Int J Environ Res Public Health. 2015;12(7): 7370-91.

\section{Submit your next manuscript to BioMed Central and we will help you at every step:}

- We accept pre-submission inquiries

- Our selector tool helps you to find the most relevant journal

- We provide round the clock customer support

- Convenient online submission

- Thorough peer review

- Inclusion in PubMed and all major indexing services

- Maximum visibility for your research

Submit your manuscript at www.biomedcentral.com/submit
Biomed Central 